\title{
Article \\ The Impact of Soil Hydrothermal Properties on Geothermal Power Generation (GPG): Modeling and Analysis
}

\author{
Zhengguang Liu ${ }^{1}\left[\right.$, Gaoyang Hou ${ }^{1}$, Ying Song ${ }^{1, *}$, Hessam Taherian ${ }^{2}\left(\mathbb{D}\right.$ and Shuaiwei Qi $^{1}$ \\ 1 Department of Power and Electrical Engineering, Northwest A\&F University, Yangling 712100, China; \\ zhengguangliu@nwafu.edu.cn (Z.L.); gyhou415@nwafu.edu.cn (G.H.); qsw1127@nwafu.edu.cn (S.Q.) \\ 2 School of Science, Engineering, and Technology, Pennsylvania State University, Harrisburg, PA 17057, USA; \\ hbt5123@psu.edu \\ * Correspondence: ysong0321@nwafu.edu.cn
}

check for updates

Citation: Liu, Z.; Hou, G.; Song, Y.; Taherian, H.; Qi, S. The Impact of Soil Hydrothermal Properties on Geothermal Power Generation (GPG): Modeling and Analysis. Energies 2022, 15, 448 .

https://doi.org/10.3390/en15020448

Academic Editor: Massimo

Dentice D'Accadia

Received: 11 November 2021

Accepted: 23 December 2021

Published: 9 January 2022

Publisher's Note: MDPI stays neutral with regard to jurisdictional claims in published maps and institutional affiliations.

Copyright: (C) 2022 by the authors. Licensee MDPI, Basel, Switzerland. This article is an open access article distributed under the terms and conditions of the Creative Commons Attribution (CC BY) license (https:// creativecommons.org/licenses/by/ $4.0 /)$.
Abstract: Geothermal power plants have become the main application that utilizes geothermal energy. The utilization of deep geothermal energy adheres great importance to the soil condition. One of the biggest challenges faced by geothermal power plant designers is to reduce the risk of soil exploration. To solve this problem, forecasting by modeling has proven to be an important tool to address the problem. In this research, a geo-model was established by modeling three geological layers with different hydraulic and thermal properties to solve the above dilemma. The layers, elevation, and fault zones were simulated using interpolation functions from an artificial dataset. The coupled porous media flow and heat transfer problem using Darcy's law, as well as heat transfer in porous media interfaces, were studied. The evolution of the flow field, hydrothermal performance, and temperature gradient were also analyzed for a period of 10 years. The results showed the recoverable thermal energy area gradually moved downwards during the 10-year simulation time. When the distance between the recharge well and the production well exceeded $200 \mathrm{~m}$, the collection efficiency was significantly decreased. After 5 years of extraction, the power generation efficiency of the heat source will be less than $9.75 \%$. These results effectively avoided the exploration cost of geothermal power plant site selection, which is significant for the efficiency improvement of geothermal energy.

Keywords: geothermal power generation; geological modeling; soil hydrothermal properties; renewable energy; geothermal energy

\section{Introduction}

Among all methods of geothermal resource development and utilization, power generation is undoubtedly the most efficient and effective choice based on the nature of geothermal energy [1]. According to previous research, under ideal circumstances, the utilization rate of modern geothermal power generation (GPG) is approximately $90 \%$, which is much higher than the 30\% rate for direct utilization [2,3]. However, the geothermal power generation system (GPGS) has not achieved optimistic growth in recent years [3]. The reason for this is that high-temperature energy needed to drive power generation stations is only found in a few geographical locations around the world [4]. Therefore, the key bottleneck is still the exploration and cost-versus-benefit assessment of geothermal plant construction [5]. When considering the construction of geothermal power plants, electromagnetic detection and drilling analysis methods cannot fully guarantee the accurate grasp of geographic information, which may easily lead to the risk of investment failure. In addition, the investment in geothermal power plants is much higher than that of traditional power plants, which makes this investment more difficult to promote [6].

To ensure a continuous and long-term energy supply, many technologies have been proposed and studied in recent research. Mauro et al. [7] used geothermal energy for street heat, and $\mathrm{Li}$ et al. [8] also used geothermal energy to enhance the heat transfer in energy 
piles. Clarke et al. [9] modeled a complex binary geothermal power plant with six decision variables and developed a design methodology. However, their research did not take the complex geothermal structures into consideration. Xia et al. discussed the critical external factors influencing the development of GPG [3]. Wang et al. [10] studied the comparative life cycle assessment of geothermal power generation systems in China. A coaxial downhole heat exchanger was modeled thermodynamically and economically in Nurdan Yildirim's research [11]. Wei et al. [12] analyzed a hot dry-rock geothermal resource power generation system based on the Kalina cycle. A technical review of wellbore heat exchangers was also conducted by Alimonti et al. [13]. According to the latest research results, the combination of numerical models and artificial geological data is a powerful method to investigate and estimate the potential of geothermal reservoirs [14]. However, most of the published research data have only focused on the improvement of heat exchangers or the return on investment in the production cycle. Less attention has been paid to the hydrothermal impact from the flow of groundwater and the geological structure of the soil [15].

For GPG power, Tomasini-Montenegro et al. performed a life cycle assessment of GPGs, which emphasized the influence of reservoir characteristics [16]. Jianyong Wang et al. underwent a thermodynamic analysis and optimization of the GPG system [17], but the soil hydrothermal properties were not taken into consideration. For the grid connection of geothermal power plants and power systems [18], it is particularly important to accurately assess future power generation and potential [19] through soil hydrological characteristics. For the future power system dominated by renewable energy, it is undoubtedly important to explore the impact of soil geological properties on geothermal power plants [20]. In addition, cogeneration and waste heat recovery [21] are also closely related to soil hydrological properties. Under normal circumstances, construction personnel used electromagnetic equipment and empirical formulas to predict the future power generation and service life of underground heat sources. However, this process has large errors and the risk of failure in estimation. A method of a numerical simulation model without manpower costs that can be used to realize this forecasting process and reduce the risk of failure are necessary.

In this research, Darcy's law and the heat transfer in the interface of porous media were used to study the coupling system of underground water and soil. A system of a layered subsurface with different geological and thermal properties has been established. Fractures, the injection, and the production side of a doublet were also included in this geo-model. This model is significant not only for policymakers and companies to evaluate the longterm production rate of a geothermal site but also for the utilization of a high-proportion renewable energy power system.

\section{Numerical Geo-Model}

\subsection{Groundwater Flow}

In the process of establishing the numerical model, the properties of soil have a significant impact on generation efficiency and investment return period [22]. However, the thermal and hydraulic properties of the subsurface are generally unknown [23]. In order to have a better description of situations during the actual production process, a model with three geological layers divided by fault zones is established. Artificial data sets are used in elevations and fault zones to simulate the real thermal structure, which contains different hydraulic and thermal properties in each layer. As shown in Figure 1, the shape and distribution of each layer is not fixed. It is worth noting that shallow geology and deep geology tend to overlap each other in places where geothermal activities are more frequent. For this reason, more obvious changes in depth are shaped in the third layer. The overall height of this model is $400 \mathrm{~m}$, but these simulated conditions are below $700 \mathrm{~m}$. This three-layer geological model are used to simulate the thermal storage layer environment underground from 700 to $1100 \mathrm{~m}$. 


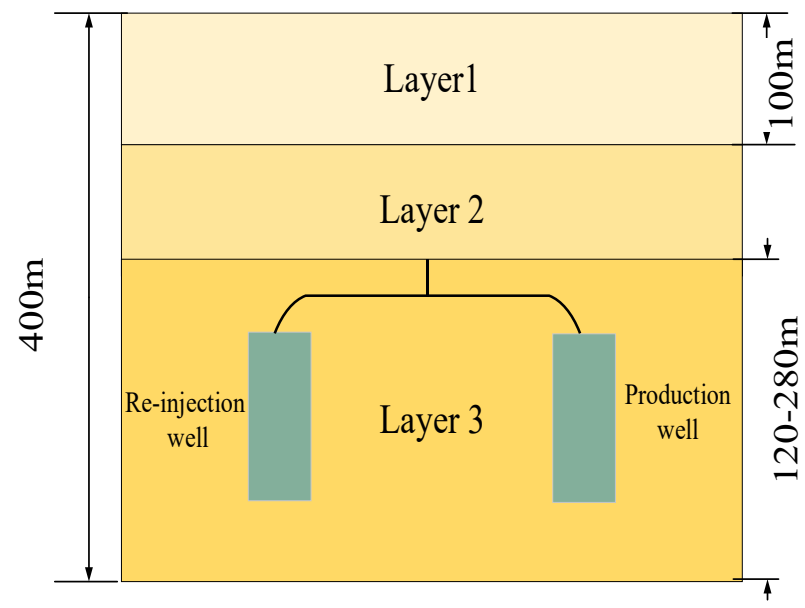

(a)

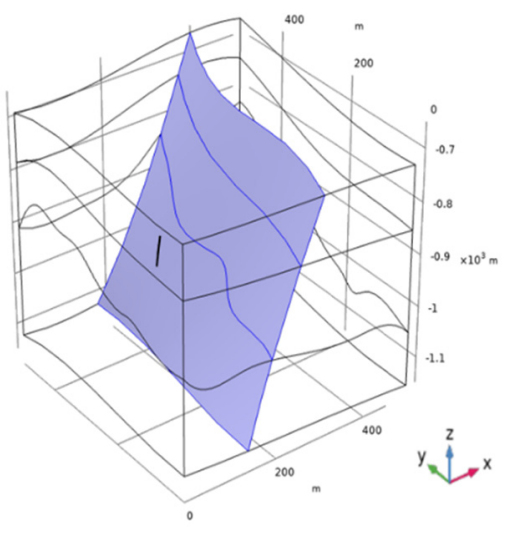

(b)

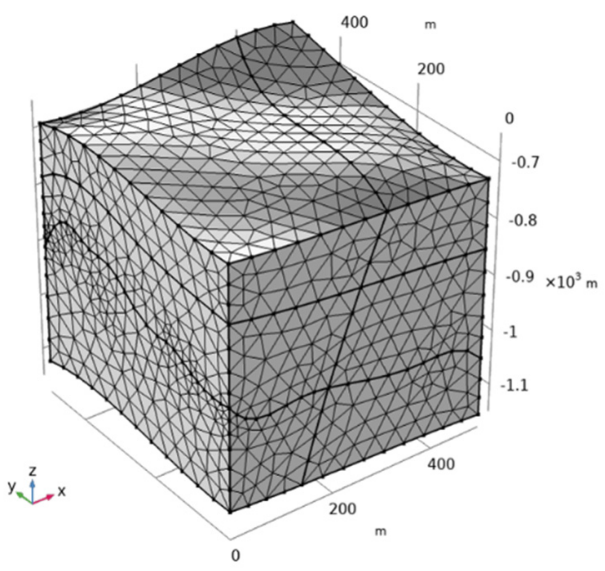

(c)

Figure 1. (a) The geothermal model with three geologic layers; (b) fracture, and the doublet's production; (c) the generated computational grid.

As geothermal power plants often use an enhanced geothermal system (EGS) to generate power, this activity makes the flow resistance in the fracture area smaller. Therefore, in groundwater flow, the water flow around the cracks is usually much faster than the flow in the soil. Based on this real condition in engineering, this paper used cubic law to simulate groundwater flows in the middle of cracks. The fracture permeability in the EGS can be described as [24]:

$$
k_{\mathrm{f}}=\frac{d_{\mathrm{f}}^{2}}{12 f_{\mathrm{f}}}
$$

In this equation, $d_{\mathrm{f}}$ is the aperture of the fracture, and the $f_{\mathrm{f}}$ describes the roughness, which is the parameter related to local soil properties. The cubic law results from the definition of the fracture's transmissivity $\left(T_{\mathrm{r}}\right)$ and can be expressed as [25]:

$$
T_{\mathrm{r}}=d_{\mathrm{f}} k_{\mathrm{f}}=\frac{d_{\mathrm{f}}^{3}}{12 f_{\mathrm{f}}}
$$

The hydraulic gradient in the $x$ direction is used as the boundary condition. The top and bottom fields are defined as the impermeable field. Two edge positions are defined as the geothermal reinjection well and the production well. The injecting water was defined by mass flow rate with $\mathrm{M}_{0}(\rho \mathrm{W} \cdot 120 \mathrm{~L} / \mathrm{s})$. This value is a common situation in geothermal 
power plants, and the specific value will vary slightly from place to place [25]. So far, we have formulated the simulation of the groundwater encountered in deep geothermal power generation plants.

\subsection{Underground Heat Transfer}

The underground conditions are complex and varying, which in turn requires several mathematical methodologies to be employed for describing the groundwater flow. For GPG, the saturated flow and pressure-driven flow in the deep geothermal layer can be solved by Darcy's law [26]:

$$
\mathrm{u}=-\frac{k_{f}}{\mu} \nabla p
$$

In Equation (3), the velocity field $u$ depends on the permeability $k_{f}$, and the dynamic viscosity $\mu$ of the fluid is driven by the pressure gradient $p$. Darcy's law is subsequently incorporated into the following continuity equation [27]:

$$
\frac{\partial}{\partial t}\left(\rho \epsilon_{p}\right)+\nabla \cdot(\rho \mathbf{u})=Q_{m}
$$

In the above equation, the term related to time can be ignored with older geological age due to the energy storage effect of water flow. The $\mathbf{u}$ can be obtained from Equation (3). Since both density $\rho$ and porosity $\epsilon_{p}$ are fixed values that can be regarded as constants, the first term on the left side of Equation (4) is 0 , the variability of density and porosity is independent of arbitrarily selected parameters, including temperature and depth. This value comes from the empirical formula, which has higher accuracy and lower error [27]. Without loss of accuracy, the variation of hydraulic properties with temperature can be ignored. Therefore, the steady-state flow equation and the time-dependent heat transfer equation are not coupled $[28,29]$. Nonetheless, when the simulated soil environment is too complex or the heat source distribution is large, especially when the degree of freedom is quite large, it makes sense for the geo-model to use this independence to split the problem into a steady-state simulation step. Underground heat transfer can be described by the following equation [30]:

$$
\left(\rho C_{p}\right)_{e q} \frac{\partial T}{\partial t}+\rho C_{p} \mathbf{u} \cdot \nabla T=\nabla \cdot\left(k_{e q} \nabla T\right)+Q+Q_{g e o}
$$

Equation (5) reveals that heat balance is achieved through the conduction and convection processes in geothermal pipelines. $C_{p}(\mathrm{~J} /(\mathrm{kg} \cdot \mathrm{K}))$ is the water heat capacity. The definition of $Q$ represents the generation or loss of heat. $Q_{\text {geo }}$ stands for the domain condition changing with the real soil condition. Temperature condition using the same geothermal gradient is active if $n \cdot \mathbf{u}<0$ (inflow) or otherwise $-n \cdot q=0$ (outflow). The vertical boundaries are defined as open boundaries. Analogous to the fracture flow boundary condition in the Darcy's law interface, the fracture boundary condition of GPG simulates the energy exchange at the heat transfer interface. Thus, in order to simulate the heat source term caused by the water injection well [31], the linear heat source feature is used:

$$
Q=C_{\mathrm{p}} \frac{M_{0}}{l}\left(T_{\mathrm{inj}}-T\right)
$$

where $l$ is the well length, $T_{\mathrm{inj}}=278 \mathrm{~K}$ is the injection temperature, and $T$ indicates the current temperature. The other setting parameters of the model are shown in Table 1. 
Table 1. Parameters of geo-model.

\begin{tabular}{cccccc}
\hline \multicolumn{2}{c}{ Geothermal Conditions } & \multicolumn{2}{c}{ Hydraulic Parameters } & \multicolumn{2}{c}{ Geo-Model Settings } \\
\hline Geothermal gradient $(\mathrm{K} / \mathrm{m})$ & -0.03 & Pumping rate $(\mathrm{L} / \mathrm{s})$ & 190 & Time (year) & 10 \\
\hline Surface temperature $(\mathrm{K})$ & 283 & Fracture thickness $(\mathrm{m})$ & 0.002 & Fracture roughness & 1.6 \\
\hline Injection temperature $(\mathrm{K})$ & 278 & Pumping rate $\left(\mathrm{m}^{3} / \mathrm{s}\right)$ & 0.12 & Borehole radius $(\mathrm{m})$ & 1 \\
\hline Water temperature $(\mathrm{K})$ & 280 & $\begin{array}{c}\text { Hydraulic gradient } \\
(\mathrm{mm} / \mathrm{m})\end{array}$ & $0 \sim 10$ & Maximum step $($ day $)$ & 0.5 \\
\hline
\end{tabular}

For the deep geothermal power generation system, the temperature distribution is usually an uncertainty factor [32]. This factor not only affects the utilization efficiency of geothermal energy but also determines the power generation efficiency. In Figure 1, a geo-model of a thermal storage layer (second layer) with a volume of about 500 cubic meters is established. This model can represent part of a geothermal mining site located on a large fault zone in EGS. Different hierarchical heights in the geo-model are processed from external artificial data sets using interpolation functions. Among them, the relevant aquifer is fully saturated. The initial surface temperature is $10^{\circ} \mathrm{C}$. The production well with a cylindrical layout on the right draws (produces) underground hot water at a rate of $50 \mathrm{~L} / \mathrm{s}$. After the extracted hot water is used to generate heat and electricity, it will flow back into the refill well on the left pipe at the same rate with a lower water temperature. Some simulation parameter settings are shown in Table 2. The values are derived from assumptions and can be changed according to actual conditions in the industrial process.

Table 2. Three layers of GPG in simulation.

\begin{tabular}{cccc}
\hline Layer & Top Layer & Middle Layer & Bottom Layer \\
\hline Porosity & 0.1 & 0.4 & 0.3 \\
Permeability $\left(\mathrm{m}^{2}\right)$ & $1 \times 10^{-10}$ & $1 \times 10^{-6}$ & $1 \times 10^{-7}$ \\
Thermal conductivity W/(m·K) & 2 & 3 & 3.5 \\
Heat capacity J $/(\mathrm{kg} \cdot \mathrm{K})$ & 900 & 850 & 850 \\
Density $\left(\mathrm{kg} / \mathrm{m}^{3}\right)$ & 1300 & 1900 & 2300 \\
\hline
\end{tabular}

\section{Electrical Analysis}

When geothermal fluid is extracted from the production well, the fluid passes through many processes on its way to the power station. Different equipment are the reason for the energy loss [33]. Because only the separated steam is used for power generation, a significant amount of heat is lost when separating steam from water. [34,35]. During the flash process, a pressure drop is applied to generate additional steam from the geothermal fluid. This process is the main reason for an increase in the silica concentration of the remaining fluid (brine). This silica would lead to a drop in conversion efficiency and high maintenance cost. Moreover, non-condensable gas (NCG) content, heat loss from equipment, generator efficiency, and power plant parasitic load will also affect the efficiency of power generation. Compared with steam without NCG, an NCG content of $1 \%$ by weight would reduce the $0.59 \%$ output [36].

$$
\eta_{n c g}=1-0.0059 C
$$

where $C$ is the content (\%) of NCG by weight. Heat loss also occurs when geothermal fluid is working in pipes, for different ambient temperatures and pipes [36]. For the turbine, the turbine efficiency drops during the steam expansion; this process can be expressed as follows [37]:

$$
\eta_{\mathrm{t}}=\eta_{\mathrm{td}} \times\left(\mathrm{a} \times \frac{\mathrm{X}_{\mathrm{in}}+\mathrm{X}_{\mathrm{out}}}{2}\right)
$$

In this equation, $\eta_{\mathrm{t}}$ is the turbine efficiency, $\eta_{\mathrm{td}}(0.83)$ is the dry turbine efficiency, $X_{\mathrm{in}}$ (1) is the turbine inlet dryness fraction (Gram/cubic meter), and $X_{\text {out }}$ is the outlet dryness 
fraction (Gram/cubic meter). The a is the Baumann factor (in this research, it equals 1). Using a combination of the factors mentioned above, the minimum power conversion efficiency can be achieved by the following formula:

$$
\eta=\dot{\mathrm{m}}_{\mathrm{s}} \times \Delta \mathrm{h} \times \eta_{\mathrm{t}} \times \eta_{\mathrm{g}} \times \eta_{\mathrm{ncg}} \times \eta_{\mathrm{apc}}
$$

where $\eta$ is the conversion efficiency, and $\dot{m}_{\mathrm{s}}$ is the steam flow rate in the turbine. $\Delta \mathrm{h}$ is the enthalpy difference between turbine inlet an outlet. $\eta_{\mathrm{g}}$ is the efficiency of gross electric power, and $\eta_{\text {apc }}$ is the efficiency of auxiliary power consumption. According to the above equations, the working efficiency of the geothermal power plant can be effectively inferred [38]. The structure diagram of the geothermal power plant is shown in Figure 2. The power generation efficiency of the entire geothermal system is not only related to the efficiency of the mentioned geothermal power generation device but also related to the soil hydrological characteristics of the pumping well. These formulas are used in COMSOL, and the specific values of the parameters can be determined by the construction conditions. The data in this study come from the geological structure of Xi'an, Shanxi.

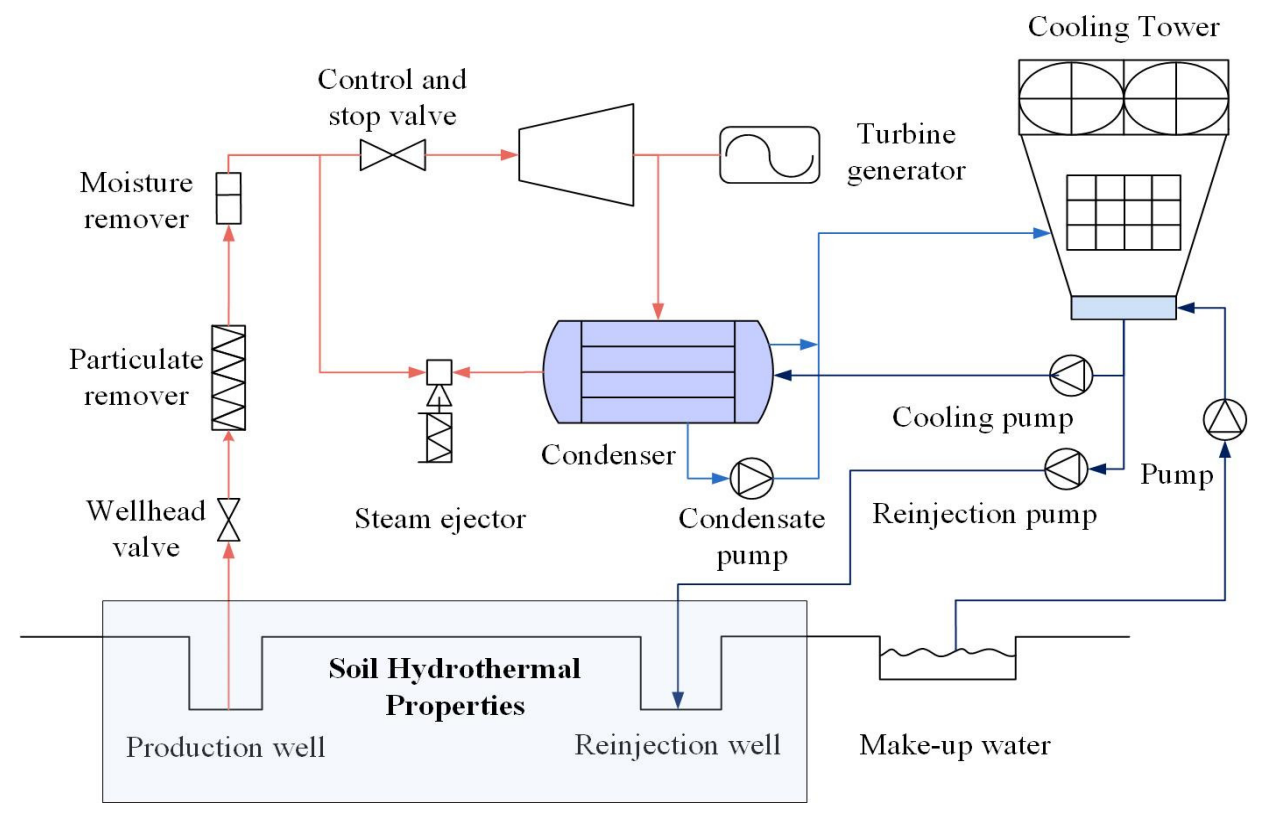

Figure 2. Simplified schematic of GPG with soil hydrothermal properties.

Different soil geological structures make the average fluid enthalpy of the produced geothermal fluid different [39]. Normally, only $10 \%$ of the energy in the produced geothermal fluid can be converted into electricity [38].

The power output for GPG can be calculated using the following equation [40]:

$$
\mathrm{W}_{\mathrm{st}}=\eta_{\mathrm{t}} \times \eta_{\mathrm{g}} \times \dot{\mathrm{m}}_{\mathrm{s}} \times \Delta \mathrm{h}
$$

where $W_{\text {st }}$ is the fluid steam turbine power output [41], $\eta_{\mathrm{t}}$ is the turbine efficiency, $\eta_{\mathrm{g}}$ is the efficiency of gross electric power, and $\dot{m}_{s}$ is the total mass of steam, $\Delta \mathrm{h}$ is the enthalpy difference between inlet and outlet fluid enthalpy.

\section{Results and Discussion}

\subsection{Distribution of Pressure and Temperature}

Soil can be set as a porous matrix in the established model in COMSOL 5.6. The default grid settings were adjusted to ensure that the accuracy of modeling the reinjection well during the simulation process. Then, Mesh was generated for the geo-model, and the observation time was set to 10 years. The production well with the cylindrical layout 
on the right draws (produces) underground hot water at a rate of $50 \mathrm{~L} / \mathrm{s}$. The pressure field distribution of the three-layer soil with groundwater area at the 10th year is shown in Figure 3. Since the pipeline will be largely affected by hydrostatic pressure, this study only sets the location of the relevant wellhead, and this part of the pipeline deformation is not reflected in the model.

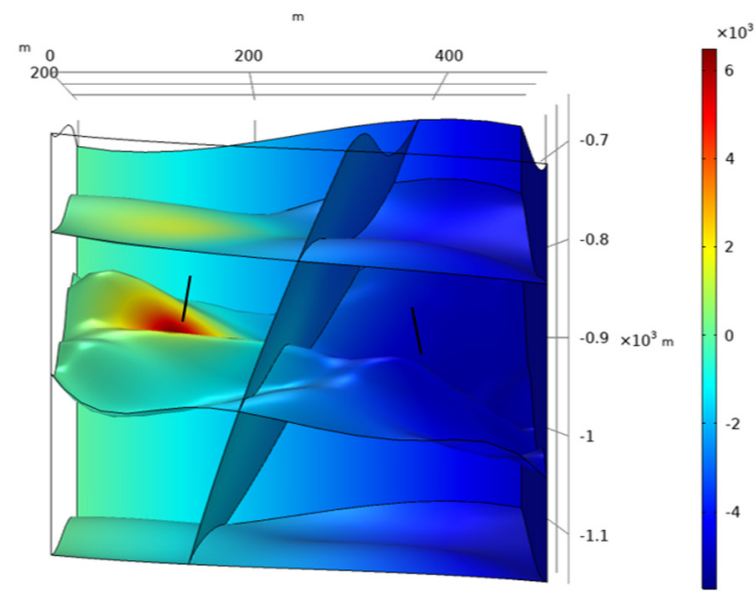

Figure 3. Pressure distribution after 10 years of simulation.

Different colors in Figure 3 indicate different pressure levels. The darker the color is, the greater is the pressure. In the GPG system, the pressure of the fluid after 10 years is still concentrated on the production and injection wellheads, which is consistent with conventional knowledge. We chose the pressure value under the normal state of the surface as a reference and recorded it as 0 pressure. The locations of the two wells are indicated in the figure. The negative pressure state indicates that the well is pumping, and the positive pressure state indicates that the well is injecting. The closer to the injection wellhead, the greater the pressure, which can exceed $6 \times 10^{3} \mathrm{~Pa}$; while the closer to the pumping wellhead, the greater the extraction pressure. The maximum extraction pressure can reach $4 \times 10^{3} \mathrm{~Pa}$. Different pressure changes will cause changes in extraction costs, thereby affecting equipment maintenance and changes in outlet water temperature.

After 10 years of geothermal energy extraction, the streamline in the Darcy velocity field and temperature distribution are shown in Figure 4; the unit of temperature is K, and the unit of pressure is Pa. Different colors in Figure 4 represent different temperature levels. After 10 years, the temperature at the middle layer is already lower than the temperature at the top and bottom. It can be found that the lowest temperature of the layer has reached $280 \mathrm{~K}$. This lower temperature will greatly facilitate our further extraction and is of great significance for us to further extract the energy contained in this formation. In the Darcy velocity field, the direction of fluid flow is from the well on the left to the pumping well on the right. The time required to reconstruct the initial temperature distribution (or reservoir enthalpy) will be determined by the local climate and soil conditions. Generally, the longer the construction period, the longer the process.

\subsection{Well Distance}

After 10 years of heat extraction, the hydrothermal connection between the recharge area and the production area is shown in Figure 3. In order to better measure the trend of the temperature gradient, the production area temperature is recorded every 2 years, as shown in Figure 5. The soil conditions in this paper are based on the soil conditions in Xi'an, Shaanxi, which may be slightly different in different regions. 


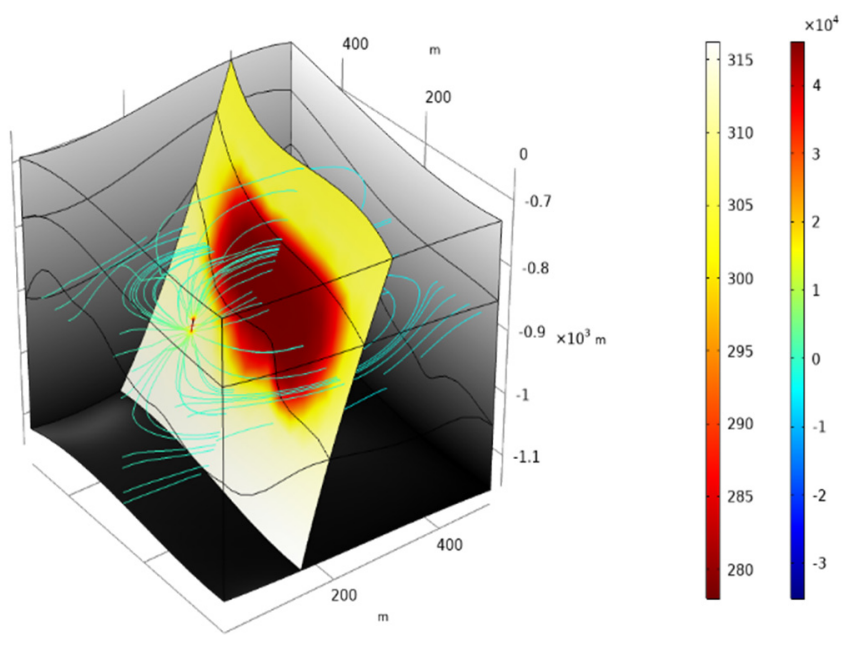

Figure 4. Temperature distribution and streamlines for GPG after 10 years (two color scales: left, temperature; right, pressure).

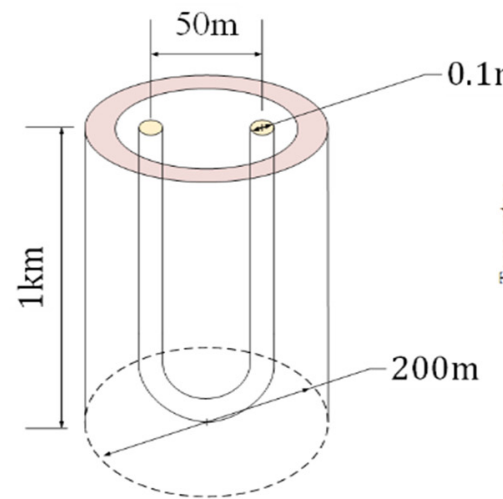

(a)

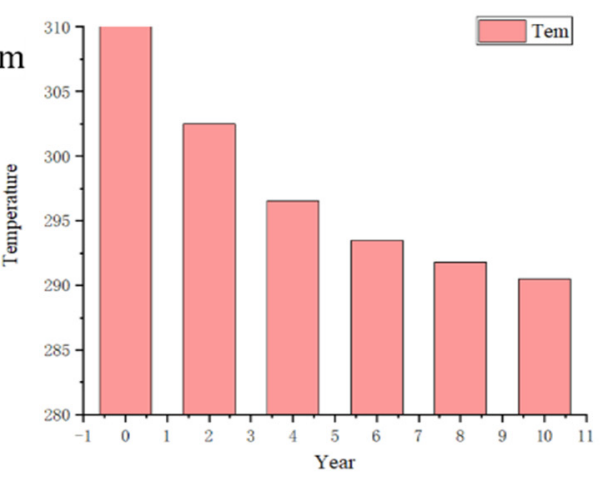

(b)

Figure 5. (a) Schematic diagram of the pipe in deep geothermal power generation; (b) variation of production temperature with fixed well distance.

When the distance between the inflow and outflow wells is fixed at $50 \mathrm{~m}$, the average change in the annual production temperature of geothermal power generation is shown in Figure 5. The left part shows the distribution of deep geothermal pipelines, and the right side records the variation of annual average production temperature. In the first 2 years, the temperature change is the most obvious, from the initial $310 \mathrm{~K}$ to $300 \mathrm{~K}$. After 3 years, the temperature drops smoothly at around $2 \mathrm{~K}$ per year. Overall, the production temperature dropped $20 \mathrm{~K}$ in 10 years. This model can effectively evaluate whether a hot spot is worth mining under different conditions. However, the lateral distance between the recharge well and the production well will also affect the mining temperature. For different lateral distances, the mining temperature changes as follows.

As shown in Figure 6, the outlet temperature changes with different well distances. The $x$-axis of Figure 6 is the distance between the wells, and the $y$-axis is the temperature that is affected by the distance between the holes. The temperature increases when the distance is between $40 \mathrm{~m}$ and $140 \mathrm{~m}$. On the other hand, when the distance is greater than $140 \mathrm{~m}$, the growth rate slows down. Moreover, the temperature rises at a much slower rate with a distance greater than $200 \mathrm{~m}$. In other words, the temperature is basically maintained at $309.65 \mathrm{~K}$ with $200 \mathrm{~m}$ or greater distance. As the distance increases, more areas are included in the geothermal power generation plant; more energy can be extracted by this strategy, which may be the reason for the increase of outlet temperature. 


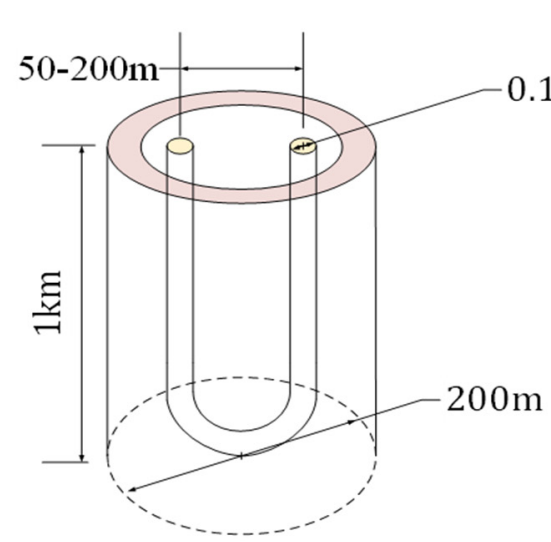

(a)

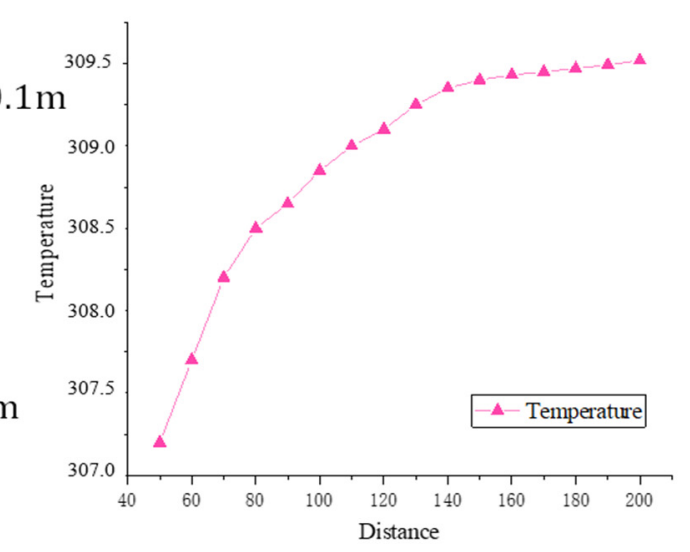

(b)

Figure 6. (a) Different well distance; (b) change in production temperature at different well distances.

Based on the simulation, we can predict the production temperature over time. At the same time, we can estimate the production life, internal investment rate, and payback period of the entire geothermal power plant because the balance of equipment cost is the same for all cases. By using this model, different geothermal power generation systems can be easily simulated by simply changing the position of the refill wells/production wells. Since the power generation efficiency of a geothermal power plant is directly related to the outlet temperature, this model can also be used to seek the maximum economic benefits for the power plant under the same mining cost.

\subsection{Electrical Impact}

As time changes, the enthalpy value of the geothermal fluid in the geothermal power plant and the corresponding power generation efficiency are shown in Figure 7. The condenser pressure is 0.12 bar abs, and the separator pressure is $6.2 \mathrm{bar}$ abs. The distance between the boreholes is set to $200 \mathrm{~m}$.

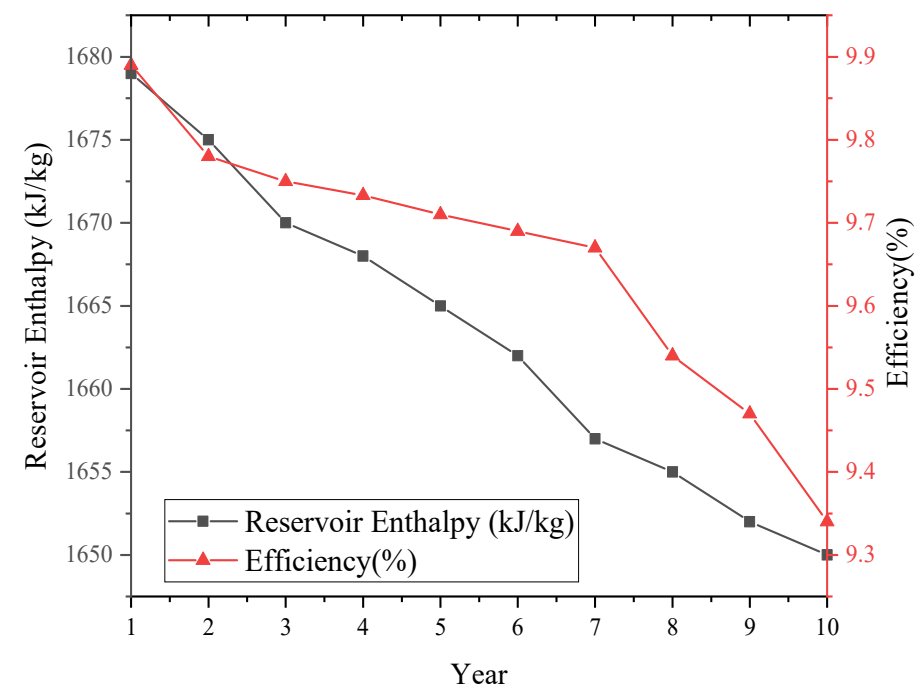

Figure 7. The efficiency and fluid enthalpy change by year.

It can be seen from Figure 7 that after the seventh year, the power generation efficiency of geothermal power plants has dropped significantly, about $0.17 \%$ per year. The enthalpy change of the thermal fluid is relatively stable, and after the first year, it drops by about $6.5 \mathrm{~kJ} / \mathrm{kg}$ per year. It is consistent with the simulation we obtained in the previous article. As time changes, the heat from the geothermal source is gradually extracted, and the 
quality of the heat source gradually declines. The rate of quality decline became faster after 5 years' mining.

Limited by the simulation area and parameters, the geothermal power generated in this research is relatively small. The annual average power generation changes of geothermal power plants are shown in Table 3. The well distance in this table is $200 \mathrm{~m}$.

Table 3. Theoretical output power change of GPG.

\begin{tabular}{cccc}
\hline Year & Power $(\mathbf{k W})$ & Year & Power (kW) \\
\hline 1 & 234.95 & 6 & 224.35 \\
2 & 232.56 & 7 & 222.84 \\
3 & 229.32 & 8 & 221.25 \\
4 & 226.71 & 9 & 220.80 \\
5 & 225.54 & 10 & 219.66 \\
\hline
\end{tabular}

In this simulation process, we can clearly find that the output power of the heat source gradually decreases with time. Although in actual industrial production, we can achieve a stable output power of geothermal power plants by adding pipelines or adjusting equipment power, the decreasing rate begins to slow down after the fifth year, about $1.2 \mathrm{~kW} /$ year, which is consistent with the changes we observed in Figures 5 and 7 . In order to effectively measure the accuracy of the model, we selected a geothermal power plant in Fengshun of Guangdong in China for comparison, which has a similar scale as this paper. Fengshun Geothermal Power Plant completed the installation of a $200 \mathrm{KW}$ generator in 1978. In 1985, its power generation dropped to $185.63 \mathrm{~kW}$. It is basically consistent with the downward trend in Table 3 , about $1.2 \mathrm{~kW} /$ year. It is proved that this model can play an effective role in future geothermal potential evaluation.

\section{Conclusions}

This paper proposed a novel geological structure model that can be used for GPG assessment based on the characteristics of soil and groundwater flow. Darcy's law and the heat transfer in porous media interface were utilized for accurate assessment. The influence of changes on the output power was firstly analyzed. The major findings are as follows:

(1) Models for underground systems with different geological and thermal properties were established, which can be used to effectively reduce exploration risks.

(2) The heat storage conditions of the geological structure after 10 years of operation based on the constructed geological model were analyzed. The outlet temperature dropped at a rate of $2 \mathrm{~K}$ per year within 10 years, which can be used to evaluate the production cycle and investment return of the power plant in the future.

(3) With a change in well distance, the outlet temperature also changes. However, when the distance exceeds $200 \mathrm{~m}$, the change is no longer obvious. This result is of great significance for the construction of geothermal power plants under different conditions.

(4) The ideal power output by the heat source gradually decreases. The rate of attenuation becomes faster after the fifth year, and efficiency is lower than $9.75 \%$. However, more geothermal power plants are considering the use of carbon dioxide to replace the original water as a working fluid. This may be a novel direction for future scholars.

Author Contributions: Conceptualization, Z.L. and G.H.; methodology, G.H.; software, Z.L.; validation, Z.L., G.H. and Y.S.; formal analysis, Z.L. and G.H.; investigation, Z.L.; resources, S.Q.; data curation, S.Q.; writing—original draft preparation, Z.L.; writing—review and editing, Y.S and H.T.; visualization, S.Q. All authors have read and agreed to the published version of the manuscript.

Funding: This research received no external funding.

Institutional Review Board Statement: Not applicable.

Informed Consent Statement: Not applicable. 
Data Availability Statement: The data presented in this study are available on request from the corresponding author. The data are not publicly available due to the reason that the related project is not completely finished.

Conflicts of Interest: The authors declare no conflict of interest.

\section{References}

1. Hou, G.; Taherian, H. Performance analysis of a hybrid ground source heat pump system integrated with liquid dry cooler. Appl. Therm. Eng. 2019, 159, 113830. [CrossRef]

2. Hou, G.; Taherian, H.; Li, L. A predictive TRNSYS model for long-term operation of a hybrid ground source heat pump system with innovative horizontal buried pipe type. Renew. Energy 2019, 151, 1046-1054. [CrossRef]

3. Xia, L.; Zhang, Y. An overview of world geothermal power generation and a case study on China-The resource and market perspective. Renew. Sustain. Energy Rev. 2019, 112, 411-423. [CrossRef]

4. Moya, D.; Aldás, C.; Kaparaju, P. Geothermal energy: Power plant technology and direct heat applications. Renew. Sustain. Energy Rev. 2018, 94, 889-901. [CrossRef]

5. Clauser, C.; Ewert, M. The renewables cost challenge: Levelized cost of geothermal electric energy compared to other sources of primary energy - Review and case study. Renew. Sustain. Energy Rev. 2018, 82, 3683-3693. [CrossRef]

6. Cui, Y.; Zhu, J.; Twaha, S.; Riffat, S. A comprehensive review on 2D and 3D models of vertical ground heat exchangers. Renew. Sustain. Energy Rev. 2018, 94, 84-114. [CrossRef]

7. Mauro, A.; Grossman, J.C. Street-heat: Controlling road temperature via low enthalpy geothermal energy. Appl. Therm. Eng. 2017, 110, 1653-1658. [CrossRef]

8. Li, Q.; Yin, Y.; Kong, L.; Qiao, L. Enhancing heat transfer in the heat exchange medium of energy piles. J. Build. Eng. 2021, 40, 102375. [CrossRef]

9. Clarke, J.; McLeskey, J.T. Multi-objective particle swarm optimization of binary geothermal power plants. Appl. Energy 2015, 138, 302-314. [CrossRef]

10. Wang, Y.; Du, Y.; Wang, J.; Zhao, J.; Deng, S.; Yin, H. Comparative life cycle assessment of geothermal power generation systems in China. Resour. Conserv. Recycl. 2020, 155, 104670. [CrossRef]

11. Yildirim, N.; Parmanto, S.; Akkurt, G.G. Thermodynamic assessment of downhole heat exchangers for geothermal power generation. Renew. Energy 2019, 141, 1080-1091. [CrossRef]

12. Wei, G.; Meng, J.; Du, X.; Yang, Y. Performance Analysis on a Hot Dry Rock Geothermal Resource Power Generation System Based on Kalina Cycle. Energy Procedia 2015, 75, 937-945. [CrossRef]

13. Alimonti, C.; Soldo, E.; Bocchetti, D.; Berardi, D. The wellbore heat exchangers: A technical review. Renew. Energy 2018, 123, 353-381. [CrossRef]

14. Zhu, J.; Hu, K.; Lu, X.; Huang, X.; Liu, K.; Wu, X. A review of geothermal energy resources, development, and applications in China: Current status and prospects. Energy 2015, 93, 466-483. [CrossRef]

15. Von Jouanne, A.; Brekken, T.K. Ocean and Geothermal Energy Systems. Proc. IEEE 2017, 105, 2147-2165. [CrossRef]

16. Tomasini-Montenegro, C.; Santoyo-Castelazo, E.; Gujba, H.; Romero, R.J.; Santoyo, E. Life cycle assessment of geothermal power generation technologies: An updated review. Appl. Therm. Eng. 2017, 114, 1119-1136. [CrossRef]

17. Wang, J.; Wang, J.; Dai, Y.; Zhao, P. Thermodynamic analysis and optimization of a flash-binary geothermal power generation system. Geothermics 2015, 55, 69-77. [CrossRef]

18. Çetin, G.; Özkaraca, O.; Keçebaş, A. Development of PID based control strategy in maximum exergy efficiency of a geothermal power plant. Renew. Sustain. Energy Rev. 2020, 137, 110623. [CrossRef]

19. Tasnin, W.; Saikia, L.C.; Raju, M. Deregulated AGC of multi-area system incorporating dish-Stirling solar thermal and geothermal power plants using fractional order cascade controller. Int. J. Electr. Power Energy Syst. 2018, 101, 60-74. [CrossRef]

20. Ghaebi, H.; Farhang, B.; Parikhani, T.; Rostamzadeh, H. Energy, exergy and exergoeconomic analysis of a cogeneration system for power and hydrogen production purpose based on TRR method and using low grade geothermal source. Geothermics 2018, 71, 132-145. [CrossRef]

21. Kanoglu, M.; Dincer, I. Performance assessment of cogeneration plants. Energy Convers. Manag. 2009, 50, 76-81. [CrossRef]

22. Hou, G.; Taherian, H.; Li, L.; Fuse, J.; Moradi, L. System performance analysis of a hybrid ground source heat pump with optimal control strategies based on numerical simulations. Geothermics 2020, 86, 101849. [CrossRef]

23. Cook, D.; Davidsdottir, B.; Petursson, J.G. Accounting for the utilisation of geothermal energy resources within the genuine progress indicator-A methodological review. Renew. Sustain. Energy Rev. 2015, 49, 211-220. [CrossRef]

24. Carey, J.W.; Lei, Z.; Rougier, E.; Mori, H.; Viswanathan, H. Fracture-permeability behavior of shale. J. Unconv. Oil Gas Resour. 2015, 11, 27-43. [CrossRef]

25. Mourzenko, V.V.; Thovert, J.-F.; Adler, P.M. Conductivity and Transmissivity of a Single Fracture. Transp. Porous Media 2018, 123, 235-256. [CrossRef]

26. Zhou, J.; Chen, Y.; Wang, L.; Cardenas, M.B. Universal Relationship Between Viscous and Inertial Permeability of Geologic Porous Media. Geophys. Res. Lett. 2019, 46, 1441-1448. [CrossRef] 
27. Chang, A.; Sun, H.; Zhang, Y.; Zheng, C.; Min, F. Spatial fractional Darcy's law to quantify fluid flow in natural reservoirs. Phys. A Stat. Mech. Its Appl. 2019, 519, 119-126. [CrossRef]

28. Unverdi, M.; Cerci, Y. Performance analysis of Germencik Geothermal Power Plant. Energy 2013, 52, 192-200. [CrossRef]

29. Xiang, S.; Wang, L.; Wang, Y.; Bi, R.; Xia, L.; Sun, X. Exploration of gradient energy-saving separation processes for ethylene glycol mixtures based on energy, exergy, environment, and economic analyses. Sep. Purif. Technol. 2021, 279, 119787. [CrossRef]

30. You, S.; Cheng, X.; Yu, C.; Dang, Z. Effects of groundwater flow on the heat transfer performance of energy piles: Experimental and numerical analysis. Energy Build. 2017, 155, 249-259. [CrossRef]

31. Liu, Y.; Hou, J.; Zhao, H.; Liu, X.; Xia, Z. Numerical simulation of simultaneous exploitation of geothermal energy and natural gas hydrates by water injection into a geothermal heat exchange well. Renew. Sustain. Energy Rev. 2019, 109, 467-481. [CrossRef]

32. Wang, J.; Wang, J.; Dai, Y.; Zhao, P. Thermodynamic analysis and optimization of a transcritical $\mathrm{CO}_{2}$ geothermal power generation system based on the cold energy utilization of LNG. Appl. Therm. Eng. 2014, 70, 531-540. [CrossRef]

33. DiPippo, R. Geothermal power plants: Evolution and performance assessments. Geothermics 2015, 53, 291-307. [CrossRef]

34. Stefánsson, V. Investment cost for geothermal power plants. Geothermics 2002, 31, 263-272. [CrossRef]

35. Dagdas, A. Performance Analysis and Optimization of Double-Flash Geothermal Power Plants. J. Energy Resour. Technol. 2006, 129, 125-133. [CrossRef]

36. Zarrouk, S.J.; Moon, H. Efficiency of geothermal power plants: A worldwide review. Geothermics 2014, 51, 142-153. [CrossRef]

37. DiPippo, R. Geothermal Power Plants: Principles, Applications, Case Studies and Environmental Impact; Butterworth-Heinemann: Oxfordshire, UK, 2012.

38. Yari, M. Exergetic analysis of various types of geothermal power plants. Renew. Energy 2010, 35, 112-121. [CrossRef]

39. Ghasemi, H.; Paci, M.; Tizzanini, A.; Mitsos, A. Modeling and optimization of a binary geothermal power plant. Energy 2013, 50, 412-428. [CrossRef]

40. Gabbrielli, R. A novel design approach for small scale low enthalpy binary geothermal power plants. Energy Convers. Manag. 2012, 64, 263-272. [CrossRef]

41. Zare, V. A comparative exergoeconomic analysis of different ORC configurations for binary geothermal power plants. Energy Convers. Manag. 2015, 105, 127-138. [CrossRef] 